\title{
The Effects of Propolis on Human Health
}

\author{
Özge Yılmaz Tekiner ${ }^{1, *}$ (D), Burcu Yeşilkaya² \\ ${ }^{1}$ Istanbul Health Sciences University (SBU) Kartal Koşuyolu High Speciality Educational and Research Hospital, \\ Istanbul, Turkey \\ ${ }^{2}$ Okan University, Institute of Health Sciences, Department of Nutrition and Dietetics, Istanbul, Turkey
}

\section{Article History}

Received 19 January 2021

Accepted 30 May 2021

First Online 07 June 2021

\section{*Corresponding Author}

Tel.: +905069804308

E-mail: ozgeyilmaz188@gmail.com

\section{Keywords}

Antioxidant

Total phenolic content

CAPE

Covid-19

\begin{abstract}
Propolis is a natural substance that honey bees collect from various plants such as poplar, palm, pine, conifer secretion, gum, resin, mucilage and leaf buds. Propolis gets its antioxidant and antimicrobial properties from its phytochemical content. The health-promoting mechanism of propolis appears to be related to its antioxidant and anti-inflammatory activity. The antioxidant activity of propolis is one of the most well-known properties. Flavonoids in propolis scavenge free radicals and protect the cell against lipid peroxidation. Propolis and its components prevent oxidative stress by increasing antioxidant enzyme activity and reducing lipid peroxidation. The first of the antibacterial effects of propolis is related to the direct action on the microorganism, the other to the stimulation of the immune system, which leads to the activation of the organism's natural defence system. The main components of propolis that offer anti-tumour potential are caffeic acid, phenethyl ester, chrysin, artepillin C, nemoroson, galangin, cardanol. These compounds are implicated in various genetic and biochemical pathways in cancer progression. At the same time, propolis has been thought to improve the inflammatory response in Covid-19 infection. Caffeic acid phenethyl ester (CAPE), a propolis component, is also known as an immunomodulating agent and helps reduce the excessive inflammatory response.
\end{abstract}

\section{Introduction}

Propolis is an apitherapeutic natural product, which is produced by honey bees in the hive after they are collected from the bark of trees, buds and sprouts of plants, does not dissolve in water, the colour changes according to the source and the age of the propolis, and is usually yellow, green and brown. Basically, it is an antiseptic that protects the beehive from microbial infections and prevents invaders from decomposing. In addition, propolis has been used in traditional medicine for centuries (Anjum et al., 2019; Gavanji \& Larki, 2015). Many records show that propolis was used by the ancient Egyptians, Persians and Romans. S.C. 466-377 Hippocrates used propolis to heal external and internal wounds and ulcers (Kuropatnicki, Szliszka, \& Krol, 2013).

\section{Chemical Composition}

Much work has been done on the chemical composition of propolis and more than 300 chemical compounds have been identified (Huang, Zhang, Wang, $\mathrm{Li}, \& \mathrm{Hu}, 2014)$. The chemical composition of propolis varies depending on the plants from which the resin, which is its main source, was collected, the climate, the harvesting season and the time elapsed after it was collected (Toreti, Sato, Pastore, \& Park, 2013). Propolis contains resin, wax, pollen, organic compounds (Aliyazicioglu, Sahin, Erturk, Ulusoy, \& Kolayli, 2013). Propolis gets its antioxidant and antimicrobial properties from the phytochemical content. Phenolic acids, flavonoids, esters, aldehydes, amino acids, vitamins, and minerals are some of the compounds (Batista et al., 2012). Propolis contains beneficial minerals as well as vitamins B1, B2, B6, C and E. 
Propolis also contains several enzymes (GomesCaravaca, Gomez-Romero, Arraez-Roman, Carretero, \& Gutierrez, 2006; Lotfy, 2006). CAPE is the main component of temperate propolis with extensive biological activity (Ahn et al., 2007). This variety of chemical composition provides an antibacterial function to propolis (Pamplona-Zomenhan, Pamplona, Silva, Marcucci, \& Mimica, 2011).

\section{Effects on Health}

Propolis has many applications in the treatment of many diseases due to its phenolic compounds and various enzymes (Biesalski et al., 2009). The healthpromoting mechanism of propolis appears to be related to its antioxidant and inflammatory activity. Clinical studies in animals and humans reported that propolis and its components have been generally well tolerated and non-toxic unless administered in very large amounts (Cornara, Biagi, Xiao, \& Burlando, 2017). However, due to the limited number of clinical studies of propolis in humans, it has been reported that attention should be paid to the dosage. There are no adequate studies on the acute and chronic toxicity of propolis. The administration of propolis at doses of 200 and $5000 \mathrm{mg} / \mathrm{g}$ body weight/day did not cause toxic deaths in experimental animals, and it was reported that the safe dose not toxic to humans was $1.4 \mathrm{mg} / \mathrm{kg}$ body weight after necessary calculations were made (Alkis et al., 2015; Burdock, 1998). However, propolis consumption is not recommended for people who are allergic to bee venom or those with bronchial asthma (Menniti-Ippolito, Mazzanti, Vitalone, Firenzuoli, \& Santuccio, 2008).

\section{Antioxidant Effect}

The antioxidant activity of propolis is one of the most well-known function. The majority of the results showed a reduction in oxidative stress markers. To reduce tissue damage caused by oxidative stress, antioxidant components have developed a protective mechanism (Bazmandegan et al., 2017; Kwon et al., 2004). Cellular metabolism produces reactive oxygen species (ROS) such as hydrogen peroxide $\left(\mathrm{H}_{2} \mathrm{O}_{2}\right)$, superoxide anion $\left(\mathrm{O}_{2}-\right)$, and reactive nitrogen species (RNS) (especially nitric oxide, NO) hydroxyl ion. While these reactive oxygen species are vital, they must be neutralized at the end of their activity. Phenolic compounds found in propolis inhibit ROS production and protect the cell against lipid peroxidation and DNA damage (Weaver et al., 2008). Propolis is developed a mechanism to prevent oxidative stress by reducing lipid peroxidation (Alkis et al., 2015). The main studies on the antioxidant properties of propolis were done in cell cultures or animals (Alkis et al., 2015; Mujica et al., 2017). There are few studies in the literature investigating the antioxidant effect of propolis on humans.
One study assessed the effect of oral administration of propolis solution (twice daily, 15 drops each time, 90 days) on oxidative stress and it was seen that the use of propolis increased the antioxidant capacity as well as improving oxidative stress (Mujica et al., 2017). Propolis has been reported to increase antioxidant capacity in diabetic rats (Zhang et al., 2014). In another study, $900 \mathrm{mg} /$ day propolis administration for 18 weeks in people with Type 2 diabetes showed an increase in total polyphenol levels. However, propolis application did not change serum glucose. Based on these results, propolis was thought to affect oxidative stress in type 2 diabetics, but not diabetes parameters (Zhao et al., 2016). In studies conducted for the effect of propolis on Parkinson's disease, it has been emphasized that propolis protects neurons against oxidative stress and realizes this mechanism (Amira \& Kunugi, 2020).

\section{Antibacterial Effect}

The antibacterial effect of propolis is characterized by its flavones content and the main flavones are pinocembrin, caffeic acid, phenethyl ester. The amount of these compounds is of great importance for antibacterial properties (Biesalski et al., 2009). The antibacterial effect occurs in two ways. Direct effect on microorganism is the first of these. The second is the activation of the organism's natural defence by stimulating the immune system (Sforcin \& Bankova, 2011). Assuming that propolis and other bee products have antibacterial activity, their combination enhances this effect. This relationship to the combination of propolis and honey collected in Egypt has been studied and it was concluded that the combination of honey containing propolis increases the antimicrobial effect for E. coli and S. aureus (Al-Waili, Al-Ghamdi, Ansari, AlAttal, \& Salom, 2012). In another study, the effect of propolis on trophozoites was evaluated in vitro. It has been reported that it prevents the growth of Giardia duodenalis trophozoites from adhering (Freitas, Shinohara, Sforcin, \& Guimarães, 2006).

Moreover, it was reported that propolis extract had an antimicrobial effect against gram-positive bacteria, but no effect against gram-negative bacteria (Arıkan \& Solak, 2019). In another study, Turkish propolis showed antibacterial effects against gram positive (Staphylococcus aureus, Bacillus cereus) and gram negative bacteria (Pseudomonas aeruginosa and Salmonella enteritidis) (Baskan, Kilic, \& Siriken, 2019). In a study conducted by Ceylan and Alic (2020), Bodrum Milas propolis region highly inhibited the S.mutans and S.typhimurium biofilm formation, especially at minimum inhibitory concentrations. In another study of propolis from different regions of Turkey's 11 was analyzed. It was found that propolis originated from the Marmara Region had a higher phenolic content and antioxidant capacity. This confirms that propolis differs according to the region, 
similar to other studies (Ozdal et al., 2019).

In a study conducted by Baltaş et al., propolis extract, one of the alternative approaches, was used to inhibit Helicobacter pylori ( $H$. pylori) and hence treat many stomach diseases (Baltas, Yildiz, \& Kolayli, 2016). It has been reported that regular consumption of propolis extract may contribute to a reduction in various types of diseases associated with $H$. Pylori (Sforcin \& Bankova, 2011). Oral mucositis is one of the most common complications after chemotherapy or local radiotherapy or a combination of both. Propolis has been reported to be effective in the prevention and treatment of oral mucositis (Ozdal et al., 2019).

\section{Antitumor Effect}

Researchers have reported that propolis has an antitumor effect in vivo and in vitro (Sforcin, 2007). Some of the components of propolis that provide antitumor potential are caffeic acid, phenethyl ester, and chrysin. These components are involved in various genetic and biochemical mechanisms to prevent cancer progression (Patel, 2016). One study reported that propolis has potential for the treatment of breast cancer due to its anti-tumour activity in human breast cancer cells. Again, in the same study, it was reported that its use in high doses may have pro-oxidant effects, not antioxidants (Xuan et al., 2014). In another study, propolis has been shown to have a cytotoxic effect on lung cancer cells (Demir et al., 2015). In addition, studies have shown that raw, water-soluble propolis combined with chemotherapeutic agents potentially minimizes postchemotherapeutic reactions, maximizes enhanced immunity and increases treatment efficacy without drug interaction (Patel, 2016). In another study, it was reported that whether propolis interacts with chemotherapeutic drugs is an issue that needs to be investigated yet and its use during chemotherapy is contradictory (Münstedt \& Männle, 2019).

In an in vitro study, the antiproliferative effects of propolis extract for human colon leukemia, prostate carcinoma and glioblastoma were evaluated and it was found that propolis extract provided a significant decrease in tumour cell concentrations (Oliveira Reis et al., 2019).

\section{Effects on Asthma}

One study showed that propolis, taken $75 \mathrm{mg} /$ day for one month, can suppress the main clinical signs of asthma, including cough, shortness of breath, airway hyperresponsiveness and fever symptoms, and improve asthma control (Mirsadraee, Azmoon, Ghaffari, Abdolsamadi, \& Khazdair, 2020). Physical examination revealed significant improvement in wheezing and the frequency of acute asthma attacks requiring emergency department or medications.
Although there is strong evidence of the potential effect of propolis on asthma in traditional medicine, no documented clinical experience of the effect of honey and propolis has been reported. In addition, the proposed mechanism of action of propolis on asthma has not yet been defined (Mirsadraee et al., 2020; Wanget al., 2009).

\section{Studies on Covid-19}

It binds to angiotensin converting enzyme 2 (ACE2), SARS-CoV-2, which is used as a resupper for invasion and replication in the host cell. This causes damage to the cell and also increases interpersonal transmission (Berretta, Silveira, Capcha, \& Jong, 2020). Therefore, ACE2 inhibitors have been seen as useful drug alternatives for Covid-19. In the study by Güler, Tatar, Yıldız, Belduz and Kolaylı (2020), showed propolis extract inhibitory effects by binding to ACE2. Inhibition of PAK1 is one of the goals to prevent the damage of Covid-19. CAPE, the main component of propolis, is one of the PAK1 inhibitors. CAPE can prevent coronavirusinduced lung damage by inhibiting PAK1 (Maruta \& He, 2020). One study aimed to develop a formulation to increase the antiviral effect of propolis against Covid19. The results showed that the optimized formula of Propolis has a significant inhibitory effect against Covid-3CL protease compared to other propolis extracts. These findings have defined propolis as a promising treatment approach against Covid-19 (Refaat, Mady, Sarhan, Rateb, \& Alaaeldin, 2020). Immunomodulation is desirable because the coronavirus dysregulates the immune response in the early stages of infection and facilitates virus replication. However, in the later stages of Covid-19, the body can develop an inflammatory response that can cause severe damage to the lungs and other organs, preventing that response through its CAPE-inhibiting mechanism of action and showing a protective effect against possible damage. Further research is needed on this subject (Berretta et al., 2020).

\section{Conclusion}

The health-promoting mechanism of propolis appears to be related to its antioxidant and antiinflammatory activity. Flavonoid and phenolic contents in propolis add many biological activities to propolis. These properties of propolis differ according to the region and the hive. High phenolic content gives propolis powerful antioxidant and anti-inflammatory effect. It reduces intracellular oxidative stress by scavenging free radicals and prevents tissue damage and DNA mutations caused by free radicals. In addition, it is considered as an alternative method to reduce the inflammatory response and interpersonal contagion in Covid-19. The health effects of propolis have been shown mainly in animal studies. Therefore human studies are needed. 


\section{References}

Ahn, M. R., Kumazawa, S., Usui, Y., Nakamura, J., Matsuka, M., Zhu, F., \& Nakayama, T. (2007). Antioxidantactivityandconstituents of propolis collected in various areas of China. FoodChemistry, 4(101), 1383-1392.

Aliyazicioglu, R., Sahin, H., Erturk, O., Ulusoy, E., \& Kolayli, S. (2013). Properties of PhenolicComposition andBiological Activity of Propolis fromTurkey. International Journal of FoodProperties, 16(2), 277-287.

Alkis, H. E., Kuzhan, A., Dirier, A., Tarakcioglu, M., Demir, E.,...... \& Cinar K. (2015). Neuroprotectiveeffects of propolisand caffeic acid phenethyl ester (CAPE) on the radiation-injured brain tissue (Neuroprotective effects of propolisand CAPE). International Journal of RadiationResearch, 13(4), 297-303.

Al-Waili N., Al-Ghamdi A., Ansari M. J., Al-Attal Y., \& Salom K. (2012). Synergistic effects of honey and propolis toward drug multi-resistant Staphylococcus aureus, Escherichia coli and Candida albicans isolates in single and polymicrobial cultures. International Journal of Medical Sciences, 9(9), 793-800.

Amira, M. A., \& Kunugi, H. (2020). Apitherapy for Parkinson's Disease: A Focus on the Effects of Propolis and Royal Jelly. Oxidative Medicine and Cellular Longevity, Article ID 1727142, https://doi.org/10.1155/2020/1727142.

Anjum S., Ullah A., Khan K. A., Attaullah M., Khan H., Ali H.,...... \& Dash C. (2019). Composition and functional properties of propolis (bee glue): A review. SaudiJournal of BiologicalSciences, 26(7), 1695-1703.

Arıkan, H. K.,\& Solak, H. H. (2019). Propolis Extract-PVA Nanocomposites of Textile Design: Antimicrobial Effect on Gram Positive and Negative Bacterias. International Journal of Secondary Metabolite, 4(3), 218-224.

Baltas N., Yildiz N., \& Kolayli S. (2016). Inhibition properties of propolis extracts to some clinically important enzymes. Journal of Enzyme Inhibition and Medicinal Chemistry, 31(S1), 52-55.

Baskan, C., Kilic, D., \& Siriken, B. (2019). Investigation of antibacterial and DNA damage inhibitory activities of propolis extract from Izmir of Turkey. Academia Journal of ScientificResearch, 7(4), 202-205.

Batista, L. L. V., Campesatto, E. A., Assis, M. L, Barbosa, A .P., Grillo, L. A., \& Dornelas, C. B. (2012). Comparative study of topical green and red propolis in the repair of wounds induced in rats. Revista do ColégioBrasileiro de Cirurgiões, 39(6), 515-520.

Bazmandegan, G., Boroushaki, M. T., Shamsizadeh, A., Ayoobi, F., Hakimizadeh, E., \& Allahtavakoli, M. (2017). Brown propolis attenuates cerebral ischemia-induced oxidative damage via affecting antioxidant enzymesystem in mice. Biomedicine \& Pharmacotherapy, 85, 503-510.

Berretta, A.,Silveira, M., Capcha, J., \& Jong, D. (2020). Propolis and its potential against SARS-CoV-2 infection mechanisms and COVID-19 disease. Biomed Pharmacother, 131: 110622.

Biesalski, H. K., Dragsted, L. O., Elmadfa, I., Grossklaus, R., Müller, M., Schrenk, D., ... \& Weber, P. (2009). Bioactive compounds: Definition and assessment of activity. Nutrition, 25(11-12), 1202-1205.
Burdock, G. A. (1998). Review of the biological properties and toxicity of bee propolis (propolis). Food and Chemical Toxicology, 36(4), 347-363.

Ceylan, O., \& Alic, H. (2020). Antibiofilm, Antioxidant and Quorum Quenching Activities of Propolis Samples from Southwest Anatolia. Bee Studies, 12(2), 27-30.

Cornara, L., Biagi, M., Xiao, J., \& Burlando, B. (2017). Therapeutic properties of bioactive compounds from different honeybee products. Frontiers in Pharmacology, 8, 412.

Demir, S., Aliyazicioglu, Y., Turan, I., Mısır S., Mentese A.,.....\& Değer O., (2015). Antiproliferative and proapoptotic activity of Turkish propolis on human lung cancer cell line. Nutrition and Cancer, 68(1), 165-172.

Freitas, S. F., Shinohara, L., Sforcin, J. M., \& Guimarães, S. (2006). In vitro effects of propolis on Giardia duodenalis trophozoites. Phytomedicine, 13(3), 170-175.

Güler, H. I., Tatar, G., Yıldız, O., Belduz, A. O., \& Kolaylı, S. (2020). Moleküler Yerleştirme Çalışması ile COVID-19 tedavisi için etanolik propolis ekstraktlarının ACE-II reseptörlerine karşı potansiyel inhibitör özelliklerinin araştırılması. Akademik Gıda, 17(4), 538-545.

Gavanji, S. \&Larki, B. (2017). Comparative effect of propolis of honey bee and some herbal extracts on Candida albicans. Chinese Journal of Integrative Medicine, 23(3), 201-207.

Gómez-Caravaca, A., Gómez-Romero, M., Arráez-Román, D., Segura-Carretero, A., \& Fernández-Gutiérrez, A. (2006).Advances in the analysis of phenolic compounds in products derived from bees. Journal of Pharmaceutical and Biomedical Analysis, 41(4), 12201234.

Huang, S., Zhang, C. P., Wang, K., Li, G. Q., \& Hu, F. (2014). Recent advances in the chemical composition of propolis. Molecules, 19(12), 19610-19632.

Kuropatnicki, A. K., Szliszka, E., \& Krol, W. (2013). Historical aspects of propolis research in modern times. EvidenceBased Complementary and Alternative Medicine. Article ID 964149, 11 pages.

Kwon, Y. S., Park, D. H., Shin, E. J., Kwon, M. S., Ko, K. H., Kim, W. K., ....... \& Jung, B .D. (2004). Antioxidant propolis attenuates kainate-induced neurotoxicity via adenosine A1 receptor modulation in the rat. Neuroscience Letters, 355(3), 231-235.

Lotfy, M. (2006). Biological activity of bee propolis in health and disease. Asian Pacific Journal of Cancer Prevention, 7(1), 22-31.

Maruta, H. H., \& He, H. (2020). PAK1-blockers: Potential Therapeutics against COVID-19. Medicine Drug Discovery. 2020;100039

Menniti-Ippolito, F., Mazzanti, G., Vitalone, A., Firenzuoli F., \& Santuccio, C. (2008). Surveillance of suspected adverse reactions to natural health products. Drug Safety, 31(5), 419-423.

Mirsadraee, M., Azmoon, B., Ghaffari, S., Abdolsamadi, A., \& Khazdair, M. R. (2020). Effect of Propolis on moderate persistent asthma: A phase two randomized, double blind, controlled clinical trial. Avicenna Journal of Phytomedicine, 11(1), 22-31. 
Mujica, V., Orrego, R., Pérez, J., Romero, P., Ovella, P., ZúñigaHernández, J.,.... \& Leiva, E. (2017). The role of propolis in oxidative stress and lipid metabolism: a randomized controlled trial. Evidence-Based Complementary and Alternative Medicine, Article ID 4272940.

Münstedt, K., \& Männle, H. (2019). Using Bee Products for the Prevention and Treatment of Oral Mucositis Induced by Cancer Treatment. Molecules, 24(17), 3023.

Oliveira Reis, J. H., Barreto, C., Cerqueira, J., Pereira dos Anjo J., Andrade L., ........ \& Machado, B. (2019). Evaluation of the antioxidant profile and cytotoxic activity of red propolis extracts from different regions of northeastern Brazil obtained by conventional and ultrasound-assisted extraction. Plos One, 14(7), 1-27.

Ozdal, T., Ceylan, F., Eroğlu, N., Kaplan, M., Olgun, E., \& Capanoglu, E. (2019). Investigation of antioxidant capacity, bioaccessibility and LC-MS/MS phenolic profile of Turkish propolis. FoodResearch International, 122, 528-536.

Pamplona-Zomenhan, L. C., Pamplona, B. C., da Silva, C. B., Marcucci, M. C., \& Mimica, L. M. (2011). Evaluation of the in vitro antimicrobial activity of an ethanol extract of Brazilian classified propolis on strains of Staphylococcus aureus. Brazilian Journal of Microbiology, 42(4), 1259-1264.

Patel, S. (2016). Emerging Adjuvant Therapy for Cancer: Propolis and its Constituents. Journal of Dietary Supplements, 13(3), 245-268.

Refaat, H., Mady, F., Sarhan, H., Rateb, H., \& Alaaeldin, E. (2020). Optimization and evaluation of propolis liposomes as a promising therapeutic approach for COVID-19. International Journal of Pharmaceutics, 592, 120028.
Sforcin, J. M. (2007). Propolis and the immune system: a review. Journal of Ethnopharmacology,113(1), 1-14.

Sforcin, J. M., \& Bankova, V. (2011). Propolis: Is there a potential for the development of new drugs?. Journal of ethnopharmacology, 133(2), 133-253.

Toreti, V. C., Sato, H. H., Pastore, G. M., \& Park, Y. K. (2013). Recent progress of propolis for its biological and chemical compositions and its botanical origin. Evidence-based Complementary and Alternative Medicine, Article ID 697390, 13 pages.

Wang, L. C., Lin, Y. L., Liang, Y. C., Yang, Y. H., Lee, J. H.,......\& Chiang, B. L.(2009). The effect of caffeic acid phenethyl ester on the functions of human monocytederived dendritic cells. BMC Immunolgy, 10(39), 1-13.

Weaver, C. M., Barnes, S., Wyss, J. M., Kim, H., Morre, D. M.,....\& Ferruzzi, M. G. (2008). Botanicals for agerelated diseases: From field to practice. The American Journal of Clinical Nutrition, 87(2), 493-497.

Xuan, H., Li, Z., Yan, H., Sang, Q., Wang, K.,.... \& Hu, F. (2014). Antitumor activity of Chinese propolis in human breast cancer MCF-7 and MDA-MB-231 cells. Evidence-Based Complementary and Alternative Medicine, 280120, 11 pages.

Zhang, N. N., Wu, J. Q., Gao, W. N., Wei, J. Y., Jiao, C.Y., Guo, C.J., \& Chang, H.(2014). The comparative study on improvement of oxidative stress in rats with diabetes mellitus by propolis from different origin. Chinese Journal of Food Hygiene, 498 (13), 1-9.

Zhao, L., Pu, L., Wei, J., Li, J., Wu, J., Xin, Z.,...... \& Guo, C. (2016). Brazilian green propolis improves antioxidant function in patients with type 2 diabetes mellitus. International Journal of Environmental Research and Public Health, 15(5), 498. 